\title{
Belgeo
}

Revue belge de géographie

\section{Editorial : Géographie des guides et récits de voyage}

\section{Patricia Aelbrecht}

\section{(2) OpenEdition}

\section{Journals}

Édition électronique

URL : http://journals.openedition.org/belgeo/7136

DOI : $10.4000 /$ belgeo. 7136

ISSN : 2294-9135

Éditeur :

National Committee of Geography of Belgium, Société Royale Belge de Géographie

Référence électronique

Patricia Aelbrecht, "Editorial : Géographie des guides et récits de voyage », Belgeo [En ligne], 3 | 2012, mis en ligne le 18 mars 2013, consulté le 22 septembre 2020. URL : http://journals.openedition.org/ belgeo/7136 ; DOI : https://doi.org/10.4000/belgeo.7136

\section{Ce document a été généré automatiquement le 22 septembre 2020}

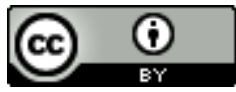

Belgeo est mis à disposition selon les termes de la licence Creative Commons Attribution 4.0 International. 


\title{
Editorial : Géographie des guides et récits de voyage
}

\author{
Patricia Aelbrecht
}

1 Les guides touristiques et les récits de voyage, qu'ils soient outils d'information descriptifs et sans état d'âme ou invitations au voyage, au rêve et à l'émotion, sont à la fois représentations spatiales, mais aussi miroirs d'une certaine manière d'appréhender le monde. Malgré leur grande diversité, ces incitateurs au voyage ont en commun de présenter deux visages : d'un côté, le discours scientifique, la description, l'observation, le reportage qui se veulent au plus près des faits concrets, de l'autre, le discours littéraire, photographique ou artistique présent pour captiver le lecteur qu'il s'agit d'accrocher. En outre, ils remplissent un rôle de conseillers pratiques et sont impliqués dans une dynamique marchande - qu'ils cherchent à se vendre eux-mêmes ou entrent dans une logique publicitaire ou de promotion des sites.

2 Interprètes des territoires, ils participent à l'élaboration du paysage et de ses représentations par l'apport d'éléments discursifs et non discursifs ainsi que par la promotion de pratiques et de processus tangibles. En effet, les images et les mythes spatiaux qu'ils propagent, aussi imaginaires et socioculturellement construits qu'ils puissent être, n'en sont pas moins reliés à la réalité et s'impriment dans les territoires par les actions qu'ils stimulent et les aménagements concrets qui découlent de ces dernières.

3 Ce numéro thématique qui leur est consacré présente un échantillon des multiples modalités d'analyse envisageables de ces sources et de leurs interactions avec les territoires.

4 Ainsi une perspective historique permet de mettre en évidence combien les deux genres - récits et guides - malgré leurs formes distinctes sont liés et se sont hybridés. Leur histoire se mêle étroitement à celle du voyage. L'approche temporelle montre l'influence des discours idéologiques et esthétiques sur la littérature de voyage alors même que ces textes se revendiquent comme objectifs, soulignant le caractère socioculturel des images spatiales qu'ils communiquent ainsi que le rôle de celles-ci 
dans le développement territorial. Si le territoire inspire les textes, ceux-ci participent à sa transformation.

5 Un autre thème abordé concerne l'aspect complexe des guides de voyages qui mêlent cartes, textes et photographies. Les discours transmis par ces différents éléments se complètent, permettant parfois de faire passer des messages contrastés.

6 Le texte touristique considéré comme un constitutif essentiel du tourisme peut être pensé en tant que situation communicationnelle. Envisagé sous cette perspective il est un lieu d'interprétations du réel ainsi que d'interactions entre des acteurs - auteur et lecteur - et des territoires. Le rôle prépondérant accordé aujourd'hui à l'expérience individuelle dans le tourisme se traduit par un déplacement progressif de l'auctorialité des rédactions des guides vers le touriste lui-même dont les récits prennent une place grandissante dans l'élaboration de ceux-ci. Les témoignages personnels deviennent la base sur laquelle sont énoncés informations, jugements de valeur, conseils. Les territoires ne sont plus interprétés par des spécialistes, mais par le voyageur commun qui par l'écrit accède à un statut de connaisseur. Mais l'évolution des guides ne s'arrête pas à ce point : plutôt que de se concentrer sur des territoires précis, certains ouvrages suggèrent à leurs lecteurs des approches originales d'appréhension de l'espace, marquant ainsi la perte d'importance de la destination au profit de l'expérience.

7 Éléments à la fois visuels et remplis de significations textuelles, les cartes constituent une composante caractéristique des guides dont le succès a participé à la vulgarisation de ces représentations abstraites et structurées de l'espace. Les envisager comme agents de spatialisation sociale permet de souligner leur rôle de médiateur des réseaux géographiques du tourisme - routes et de destinations - réseaux qui influencent les pratiques touristiques et sous-tendent les constructions spatiales imaginaires plus stimulées par les récits et les images.

8 Alors que le contenu textuel des guides tend encore souvent à être énoncé de telle façon qu'il donne une impression d'objectivité et de neutralité, les photographies transmettent un message engageant émotionnellement le lecteur. Harmonie, esthétique, caractère grandiose des sites sont imposés par des images qui invitent au rêve et à la contemplation et à l'aventure, chargeant d'imaginaires des mots plus distants.

9 Il importe aussi de ne pas perdre de vue que les guides s'inscrivent dans une logique marchande et s'adressent à des publics bien ciblés. Volontairement ou à leur insu, ils transmettent les valeurs idéologiques en vogue en feignant que celles-ci émanent des choses rencontrées. En cela, ils "authentisent" les positions conventionnelles pour leurs lecteurs. Censés rendre compte de la globalité de la réalité, leurs auteurs n'en proposent cependant qu'une interprétation partielle qui répond aux souhaits de leurs lecteurs. Ils s'inspirent souvent de ce que d'autres ont écrit avant eux, mais ils écrivent toujours ce que d'autres ont envie de lire. Les représentations des territoires parfois initiées et supportées par des institutions locales, non seulement influencent les comportements touristiques, mais collaborent aussi à la construction identitaire des populations des lieux concernés.

Omniprésents dans une société où voyager va de soi, les récits et guides touristiques participent à la transmission d'imaginaires géographiques historiquement situés ainsi que culturellement et socialement induits. Si seule la littérature de voyage publiée sur papier est envisagée ici, il faut cependant mentionner les formes virtuelles de guides et récits dont le succès va croissant. Ceux-ci se placent dans une logique d'ubiquité étant 
donné les supports communicationnels en jeu modifiant les rapports au temps et à l'espace du voyage. Peu importe qu'ils soient de papier ou de bits, les textes touristiques sont des actants géographiques dans la construction des territoires qu'ils interprètent.

\section{AUTEUR}

\section{PATRICIA AELBRECHT}

Université Libre de Bruxelles, paelbr@gmail.com 